\title{
Flora da Usina São José, Igarassu, Pernambuco: Passifloraceae s.s.
}

\author{
Flora of Usina São José, Igarassu, Pernambuco: Passifloraceae s.s.
}

\author{
Diogo Araújo ${ }^{1,2}$ \& Marccus Alves ${ }^{1}$
}

\begin{abstract}
Resumo
Passifloraceae s.s. compreende cerca de 16 gêneros e 700 espécies. No Brasil ocorrem quatro gêneros. Destes, o mais representativo é Passiflora, com mais de 130 espécies. O presente estudo contribui com o conhecimento da flora dos remanescentes florestais ocorrentes na porção norte da Floresta Atlântica sendo parte da série de monografias elaboradas para a Usina São José (USJ), além de atualizar as informações sobre a diversidade da família na região. Foram registradas dez espécies pertencentes ao gênero Passiflora e são apresentadas chave de identificação, descrições, ilustrações e comentários para cada táxon.

Palavras-chave: florística, trepadeiras, liana, Mata Atlântica, taxonomia.
\end{abstract}

\begin{abstract}
Passifloraceae s.s. comprise more than 700 species and 16 genera. In Brazil four genera are registered and Passiflora L. is the most representative with over than 130 species. This study contributed to knowledge of the flora of Passiflora from Usina São José (USJ), updating the information about the diversity of this genus in the Northeast. We recorded ten species of Passiflora. Identification key, descriptions, illustrations and comments on each taxon are presented here.
\end{abstract}

Key words: Atlantic rainforest, floristic, liana, vine, taxonomy.

\section{Introdução}

Após a inclusão de Turneraceae e Malesherbiaceae, a família Passifloraceae s.l. passou a somar 935 espécies divididas entre 27 gêneros, distribuídas principalmente nas zonas tropicais e subtropicais do mundo, em especial na América e África (APG III 2009). A subfamília Passifloroideae (Passifloraceae sensu stricto) é a mais diversa em espécies e engloba 16 gêneros e mais de 700 espécies de distribuição pantropical. Segundo Cervi et al. (2011), no Brasil ocorrem quatro gêneros: Ancistrothyrsus Harms (1 sp.) e Dilkea Mast. (3 spp.), restritos à Amazônia, Mitostemma Mast. (2 spp.), endêmico do Brasil e Passiflora L. (135 spp.) o mais representativo e amplamente distribuído. São plantas encontradas preferencialmente em formações florestais úmidas, além da Caatinga e do Cerrado.

Os esforços científicos em Passiflora L. estão mais relacionados ao aumento da produtividade de espécies cultivadas, tanto alimentícias como ornamentais (Ulmer \& MacDougal 2004). No Brasil, conhecidas como "maracujás", diversas espécies são comestíveis e apreciadas regionalmente. Também são amplamente conhecidas pelo seu efeito calmante devido à ação da passiflorina (Yoshikawa et al. 2000), de estrutura química muito similar à morfina (Yoshikawa et al. 2000). Entretanto, apenas $P$. edulis Sims é cultivada em larga escala.

O presente estudo vem a contribuir para a identificação das espécies do gênero no complexo de fragmentos florestas da Usina São José (USJ) em continuidade à série de grupos taxonômicos monografados para a área (Alves-Araújo \& Alves 2010; Melo et al. 2010; Pontes et al. 2010; Buril \& Alves 2011; Amorim \& Alves 2011; Pessoa \& Alves, no prelo).

\section{Material e Métodos}

$\mathrm{O}$ estudo foi realizado em seis fragmentos de Floresta Atlântica da USJ, localizados no município de Igarassu, Pernambuco

\footnotetext{
${ }^{1}$ Universidade Federal de Pernambuco, Depto. Botânica, Centro de Ciências Biológicas, 50670-901, Recife, PE, Brasil.

${ }^{2}$ Autor para correspondência: diogoambientais@gmail.com
} 
$\left(7^{\circ} 40 ’ 21,25^{\prime \prime}-7^{\circ} 55^{\prime} 50,92^{\prime \prime}\right.$ S e $34^{\circ} 54^{\prime} 14,25^{\prime \prime}$ $\left.35^{\circ} 05^{\prime} 21,08^{\prime \prime} \mathrm{W}\right)$ e imersos em uma matriz de cana-de-açúcar (Alves-Araújo et al. 2008, Araújo \& Alves 2010).

As coletas foram realizadas entre fevereiro de 2007 e junho de 2011, sendo as amostras botânicas processadas de acordo com técnicas usuais em taxonomia vegetal (Mori et al. 1985) e depositadas no herbário UFP, com duplicatas distribuídas para o IPA, CEPEC, RB e HVASF.

Os estudos taxonômicos foram complementados com análise do acervo dos herbários UFP, IPA, HST, PEUFR, CEPEC, RB, JPB e MAC e as identificações realizadas com o auxílio de bibliografia específica (Killip 1938; Cervi 1997; Deginani 2001; Ulmer \& MacDougal 2004; Nunes \& Queiroz 2006). Para a terminologia morfológica foi utilizado Gonçalves \& Lorenzi (2007), bem como a bibliografia específica citada anteriormente. O modelo de apresentação dos resultados segue o adotado nas monografias anteriores realizadas para a área (AlvesAraújo \& Alves 2010; Melo et al. 2010; Pontes et al. 2010; Buril \& Alves 2011; Amorim \& Alves 2011).

\section{Resultados e Discussão}

De acordo com Cervi et al. (2011), são conhecidas 15 espécies da família Passifloraceae para Pernambuco, sendo 11 delas referidas para a Floresta Atlântica. Dez táxons foram registrados na USJ, todos pertencentes à Passiflora, adicionando uma espécie (Passiflora foetida L.) ao inventário de trepadeiras realizado na área por Araújo \& Alves (2010), além de duas novas ocorrências para a Floresta Atlântica do estado: $P$. silvestris Vell. e $P$. watsoniana Mast. Passiflora silvestris representa uma nova ocorrência para o estado, elevando para 16 o número de espécies de Passifloraceae conhecidas para Pernambuco.
A maioria das espécies é amplamente distribuída na Floresta Atlântica Nordestina, ocorrendo em bordas de mata e expostas ao sol, como $P$. cincinnata Mast. e $P$. watsoniana Mast.; à sombra, no interior dos fragmentos, como $P$. contracta Vitta e P. misera Kunth; além de áreas de capoeira ou fortemente associadas à presença humana, como P. edulis Sims. e P. foetida L. Algumas espécies, como $P$. alata Curtis e $P$. suberosa L. , podem ser consideradas raras no local devido a baixa incidência de coletas apesar do continuo esforço amostral.

\section{Tratamento taxonômico Passiflora L.}

Trepadeiras herbáceas ou lenhosas. Estípulas lineares, linear-subuladas ou foliáceas, persistentes ou caducas. Pecíolo com ou sem glândulas, sésseis ou estipitadas. Folhas inteiras a 2-5-lobadas, às vezes com glândulas na margem ou nos sinus. Pedúnculos axilares, solitários ou pareados, 1-2-floros, raro racemos 7-floros; brácteas alternas ou verticiladas. Sépalas e pétalas semelhantes na forma, sépalas cartáceas a coriáceas, externamente verdes e internamente da mesma cor das pétalas; pétalas membranáceas, raro ausentes. Corona 1-a multisseriada, membranosa ou filamentosa, filamentos frequentemente claviformes; opérculo membranáceo, às vezes ausente; límen anelar, soldado ou não ao androginóforo ou cupuliforme, membranáceo ou coriáceo, raro ausente; anel nectarífero em geral presente; androginóforo alongado, raro inconspícuo; ovário 3-4-carpelar, estiletes 3-4. Frutos bagas, placentação parietal; sementes múltiplas, foveoladas, reticuladas ou alveoladas, as vezes transversalmente sulcadas, arilo mucilaginoso.

\section{Chave de Identificação para Passifloraceae da Usina São José}

1. Pecíolo eglanduloso.

2. Tricomas glandulares no caule, estípulas, lâmina foliar e brácteas; folhas 3-lobadas

2'. Tricomas glandulares ausentes; folhas $2-3$ lobadas, lobo central sempre reduzido 7. P. misera

1'. Pecíolo glanduloso.

3. Glândulas peciolares sésseis.

4. Folhas inteiras.

5. Caule 4-angulado, estípulas foliáceas oblongo-lanceoladas a oval-lanceoladas

5'. Caule cilíndrico; estípulas lineares a linear-subuladas.

6. Folhas de margem serreada; Flores solitárias 5. P. edulis 
6'. Folhas de margem inteira; Flores dispostas em racemos

3. P. contracta

4'. Folhas lobadas.

7. Folhas 3-5-lobadas; glândulas do pecíolo basais; corona inteiramente cerúlea, variegada ... 2. P. cincinnata

7'. Folhas 3-lobadas; glândulas dos pecíolos apicais; corona cerúlea na metade basal, não variegada 5. P. edulis

3'. Glândulas peciolares estipitadas.

8. Caule e folhas pubescentes

9. P. suberosa

8'. Caules e folhas glabros.

9. Folhas inteiras

8. P. silvestris

9'. Folhas 3-lobadas.

10. Brácteas róseas, obovadas a espatuladas, persistentes

10 '. Brácteas verdes, lineares, caducas

4. P. edmundoi

10. P. watsoniana

1. Passiflora alata Curtis, Bot. Mag. 2: pl. 66. 1788.

Figs. 1a-b, 2a

Caule 4-angulado. Estípulas foliáceas, oblongo-lanceoladas a oval-lanceoladas, margem inteira, persistentes. Pecíolo 2-4-glanduloso, glândulas sésseis, globosas, amarelas a alaranjadas, centro-apicais. Folhas cartáceas, inteiras, glabras, ovais a oval-oblongas, ápice agudo, raro emarginado, base cordada a truncada, margem inteira. Flores pêndulas, solitárias; brácteas verticiladas, verdes, ovadas, 2-glandulosas na margem, persistentes; hipanto campanulado; sépalas corniculadas; pétalas avermelhadas; corona 4-6-seriada, filamentosa, rósea, séries externas 2 , variegadas, ápice ondulado, internas 2-4, claviformes; opérculo de margem denticulada; límen anelar, soldado ao androginóforo, membranáceo; androginóforo reto; ovário elipsoide a obovoide, glabro; estiletes 3 . Fruto obovoide a piriforme, glabro; sementes cordiformes, alveoladas. Material examinado: Mata de Zambana, 19.X.2007, fr., A. Alves-Araújo et al. 687 (UFP, IPA, HVASF); Mata de Piedade, 21.11.2002, fr., G.J. Bezerra 110 (UFP); 26.II.2003, fl., G.J. Bezerra 122 (UFP).

Ocorre no centro-leste da América do Sul, sendo amplamente distribuída no Brasil (Ulmer \& MacDougal 2004). Na USJ tem registro em bordas florestais de solo argiloso e inundável. Floresce entre abril e janeiro e frutifica de setembro a dezembro.

Pode ser confundida com P. quadrangularis L. devido ao caule 4-angulado, porém, se distingue pelo número de glândulas peciolares, $2-4$, enquanto P. quadrangularis possui 6 .

2. Passiflora cincinnata Mast., Gard. Chron. 37 : 966. 1868.

Figs. 1c, 2b-c

Caule cilíndrico, glabro. Estípulas linearsubuladas, persistentes. Pecíolo 2-glanduloso, glândulas sésseis, pateliformes, basais. Folhas membranáceas, 3-5-lobadas, glabras, ápices agudos, mucronados, base aguda, margem inteira. Flores eretas, solitárias; brácteas verticiladas, verdes, oval-lanceoladas, convexas, persistentes, 2-glandulosas na base; hipanto curto-campanulado, sépalas corniculadas; pétalas violáceas; corona multi-seriada, filamentosas, cerúlea, séries externas 2 , ápice ondulado, variegadas, séries intermediárias curtas, purpúreas, séries internas 2, claviformes; opérculo liso, margem filamentosa; límen anelar, livre; androginóforo reto; ovário globoide, glabro; estiletes 3. Fruto globoide, glabro; sementes ovaladas, reticulado-foveoladas.

Material examinado: Mata de Zambana, 28.VII.2007, fl. e fr., N. Albuquerque 457 (IPA).

Material adicional examinado: BRASIL. BAHIA: Riacho das Neves, São José do Rio Branco, 12.III.2010, fl., K. Yoshida-Arns et al. BHRG-465 (UFP).

Amplamente distribuída na América do Sul, inclusive no Brasil, onde ocorre em florestas estacionais, caatingas e cerrados (Nunes \& Queiroz 2006). Na USJ foi registrada em bordas de fragmentos, ocorrendo em áreas de cultivo adjacentes. Floresce e frutifica o ano inteiro.

Passiflora caerulea L. (que não ocorre na área estudada) pode ser confundida com $P$. cincinnata por ambas possuírem folhas 5-lobadas. No entanto, a primeira possui pecíolo 4-glanduloso e brácteas não convexas.

3. Passiflora contracta Vitta, Brittonia 56(1): 8995. 2004.

Fig. $2 d$

Caule cilíndrico, glabro. Estípulas linearsubuladas, caducas. Pecíolo 2-glanduloso, glândulas sésseis, elípticas, negras, basais. Folhas cartáceas, inteiras, glabras, elípticas a elíptico-oblongas, ápice acuminado, base aguda, margem inteira. Flores sésseis, eretas, em racemos pêndulos, às vezes caulifloros; 

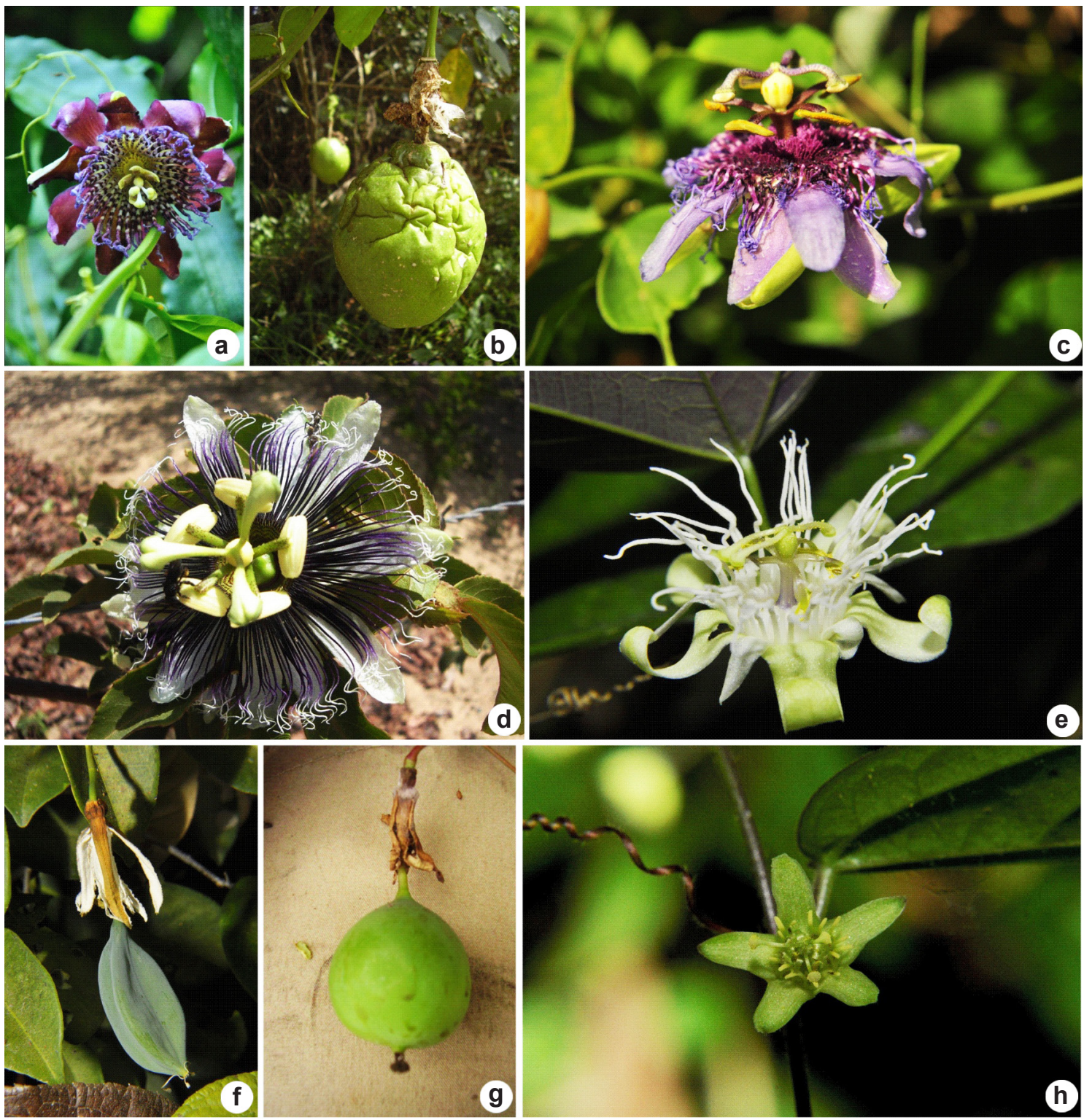

Figura 1 - a-b. Passiflora alata - a. flor; b. fruto imaturo. c. P. cincinnata - flor. d. P. edulis - flor. e. P. misera flor. f. P. silvestris - fruto imaturo. g. P. watsoniana - fruto. h. P. suberosa - flor. (a Alves-Araújo 687, b Bezerra 122, c Albuquerque 457, d Araújo 577, e Araújo 348, f Araújo 478, g Araújo 197, h Irapuan 21).

Figure 1 - a-b. Passiflora alata - a. flower; b. immature fruit. c. P. cincinnata - flower. d. P. edulis - flower. e. P. misera - flower. f. P. silvestris - immature fruit. g. P. watsoniana - fruit. h. P. suberosa - flower. (a Alves-Araújo 687, b Bezerra 122, c Albuquerque 457, d Araújo 577, e Araújo 348, f Araújo 478, g Araújo 197, h Irapuan 21).

brácteas verticiladas, verdes, lineares, eglandulosas, persistentes; bractéolas inconspícuas, na junção pedúnculo-pedicelo; hipanto cupuliforme; sépalas, não corniculadas, pétalas brancas; corona 2-seriada, série externa membranosa, série interna filamentosa, filiforme; opérculo plicado, margem filamentosa; límen anelar, crasso, livre androginóforo; anel nectarífero ausente; androginóforo recurvado; ovário oblongo-elipsoide, hirsuto; estiletes 4. Fruto ovoide, glabro; sementes elípticas, oblongas, reticuladas.

Material examinado: Mata dos Macacos, 15.VI.2007, fl., D. Araújo et al. 310 (UFP, IPA); Mata de Piedade, 26.III.2008, fl., fr., A. Melo 237 (UFP); 29.VII.2007, fl., $D$. Araújo et al. 388 (UFP); Mata de Zambana, 22.XII.2007, fr., D. Araújo et al. 576 (UFP, IPA). 

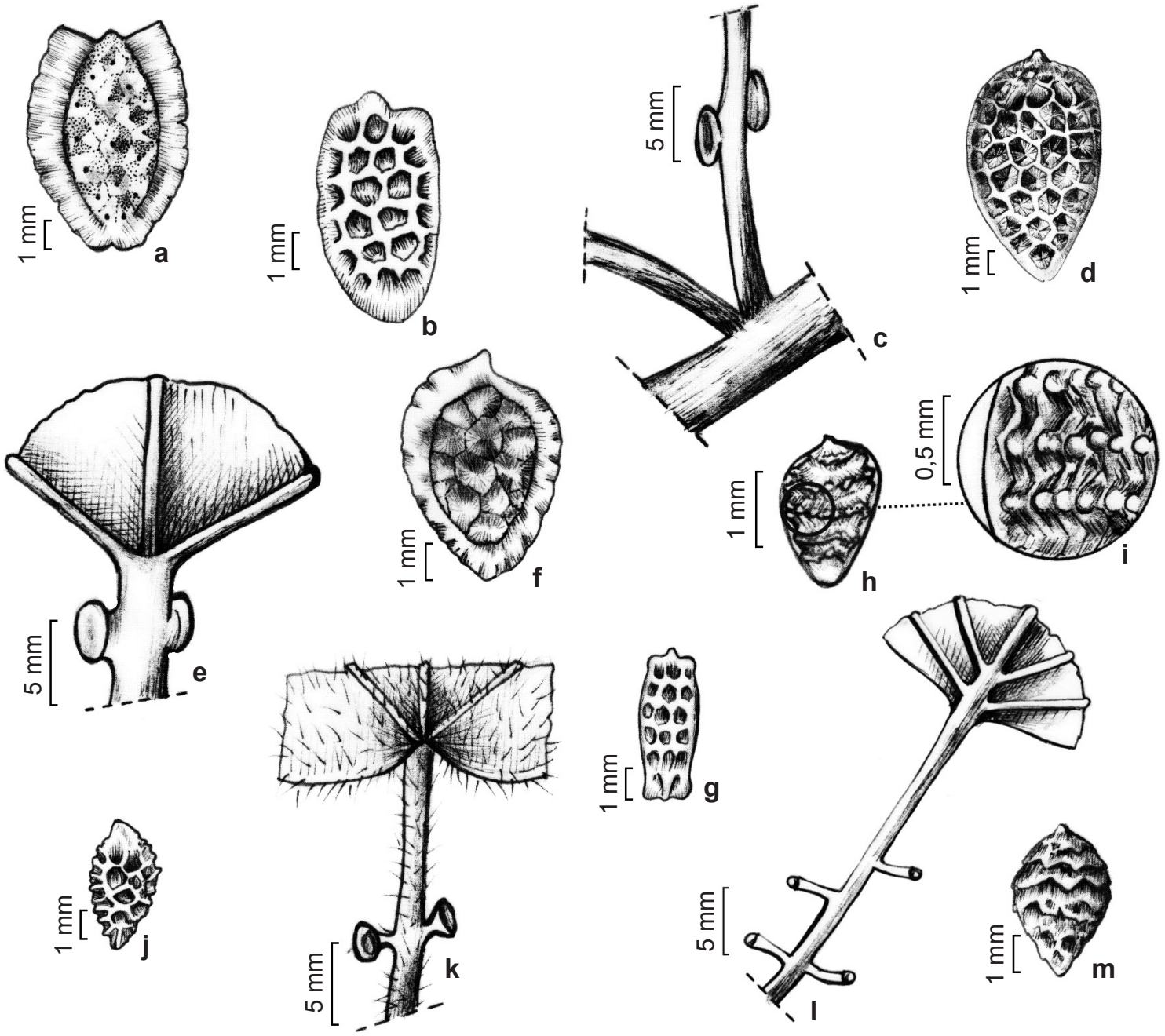

Figura 2 - a. Passiflora alata - semente. b-c. P. cincinnata - b. semente; c. base do pecíolo. d. $P$. contracta-semente. e-f. $P$. edulis - e. ápice do pecíolo; f. semente. g. $P$. foetida - semente. h-i. $P$. misera -h. semente; i. detalhe da semente.j. $P$. silvestris -semente. k. P. suberosa-ápice do pecíolo. 1-m. P. watsoniana-1. pecíolo; m. semente. (a Alves-Araújo 687, b-c Albuquerque 457, d Araújo 576, e-f Araújo 56, g Araújo 139, h-i Machado (UFP 48029), j Araújo 478, k Irapuan 21, 1-m Araújo 197).

Figure 2 - a. Passiflora alata - seed. b-c. P. cincinnata - b. seed; c. petiole basis. d. P. contracta - seed. e-f. P. edulis - e. petiole apex; f. seed. g. $P$. foetida-seed. h-i. P. misera-h. seed; i. detail of seed. j. P. silvestris - seed. k. P. suberosa-petiole apex. 1-m. P. watsoniana-1. petiole; m. seed. (a Alves-Araújo 687, b-c Albuquerque 457, d Araújo 576, e-f Araújo 56, g Araújo 139, h-i Machado (UFP 48029), j Araújo 478, k Irapuan 21, 1-m Araújo 197).

Endêmica da Floresta Atlântica do Espírito Santo até Pernambuco (Vitta \& Bernacci 2004). Na USJ foi encontrada no interior dos fragmentos. Floresce e frutifica o ano inteiro.

Pode ser confundida com $P$. ovalis Vell. por possuir 4 estiletes, porém esta pode ser diferenciada pelas flores pediceladas.

\section{Passiflora edmundoi Sacco, Sellowia 18: 3-5. 1966.}

Caule cilíndrico. Estípulas foliáceas, reniformes, mucronadas, margem levemente serreada, persistentes. Pecíolo 4-glanduloso, glândulas estipitadas, filiformes, dispersas. Folhas membranáceas, 3-lobadas, glabras, ápices emarginados a agudos mucronados, base subpeltada, margem inteira a levemente serreada, glândulas-2-4 em cada sinus. Flores eretas, solitárias; brácteas alternas, róseas, obovadas a espatuladas, eglandulosas, persistentes; hipanto cilíndrico, base dilatada, sépalas e pétalas reflexas na ântese; sépalas corniculadas; pétalas vermelhas; corona 2-seriada, série externa filamentosa, raro membranosa, série interna membranosa, tubulosa; opérculo plicado, filamentoso no ápice; límen 
anelar, soldado ao androginóforo; androginóforo reto; ovário elipsoide a fusiforme; estiletes 3 . Fruto elipsoide, glabro; sementes oblongas, alveoladas. Material examinado: Mata de Piedade, fl., A. Silva (IPA-61585).

Endêmica do Brasil, ocorre no Piauí, Bahia, Goiás, Minas gerais e Rio de Janeiro (Cervi 1997). É possivelmente cultivada como ornamental nos arredores da USJ, com ocorrência espontânea nos fragmentos florestais adjacentes. No estado de Pernambuco floresce e frutifica etre outubro e maio.

É frequentemente confundida com $P$. kermesina Link \& Otto, restrita à Região Sudeste. Porém, esta se diferencia por possuir corona 3-4-seriada com todas as séries filamentosas.

5. Passiflora edulis Sims., Bot. Mag. 45: tab. 1989. 1818.

Figs. 1d, 2e-f

Caule cilíndrico, glabro a glabrescente. Estípulas lineares, caducas. Pecíolo 2-glanduloso, glândulas sésseis, circulares, verdes, apicais. Folhas cartáceas, nítidas, 3-lobadas, raro inteiras, glabras, ápices e base agudos, margem serreada, glândulas na margem e nos sinus. Flores eretas, solitárias; brácteas verticiladas, verdes, ovais a oblongas, 2-glandulosas, persistentes; hipanto campanulado; sépalas corniculadas, glândulas 2, sésseis no ápice; pétalas brancas; corona 5-seriada, filamentoso-filiforme, séries externas 2 , cerúleas na metade basal, brancas na metade apical, séries internas 3; opérculo membranoso, margem filamentosa; límen cupuliforme, crasso; androginóforo reto; ovário ovoide-elipsoide, velutino; estiletes 3. Fruto globoide, glabro; sementes ovadas, reticuladas a foveadas.

Material examinado: Mata de Piedade, 10.I.2008, fl., D. Araújo et al. 577 (UFP, IPA).

Material adicional examinado: BRASIL. PERNAMBUCO: Buíque, Vale do Catimbau, 28.I.2006, fl.e fr., D. Araújo 56 (UFP).

Nativa do Brasil, sendo amplamente distribuída e cultivada extensivamente em muitos países tropicais (Nunes \& Queiroz 2006). Na USJ, foram observados indivíduos espontâneos nas bordas florestais e possivelmente originários de cultivos nos arredores. Floresce e frutifica o ano inteiro.

Raras amostras de P. edulis apresentam folhas inteiras e neste caso podem ser confundidas com P. alata, mas diferenciam-se pelo caule cilíndrico e margem foliar serreada.

\section{Passiflora foetida L., Sp. pl. 2: 959. 1753.}

Fig. $2 \mathrm{~g}$

Caule cilíndrico, glabrescente a hirsuto, tricomas simples e glandulares. Estípulas foliáceas, reniformes, pinatissectas, tricomas glandulares, persistentes. Pecíolo eglanduloso. Folhas membranáceas, 3-lobadas, pilosas, ápice agudo, base cordada, margem serreada, glandular-ciliada. Flores eretas, solitárias ou aos pares; brácteas verticiladas, verdes, pinatissectas, tricomas simples e glandulares na margem, persistentes; hipanto curtocampanulado; sépalas corniculadas; pétalas brancas a branco-esverdeadas; corona 5-seriada, filamentosa, séries externas 2 , filiformes, brancas, base vinácea a purpúrea, séries internas 3 , claviformes; opérculo membranoso, margem denticulada, verrucosa; límen cupuliforme, membranáceo; androginóforo reto; ovário globoide, hirsuto, raro glabrescente; estiletes 3. Frutos globoide a elipsoide, piloso; sementes oblongas, achatadas dorsiventralmente, alveoladas. Material examinado: Mata de Piedade, 26.XI.2010, fl., D. Araújo 1138 (UFP).

Material adicional: Ibateguara, Usina Serra Grande, VII.2006, fl. e fr., D. Araújo 139 (UFP).

Amplamente distribuída na América tropical, assim como no Brasil (Deginani 2001). Na USJ foi registrada em áreas de capoeira e frequentemente como invasora de cultivo. Apresenta alta plasticidade fenotípica, o que dificulta a delimitação morfológica de entidades infraespecíficas (Araújo \& Alves 2007). Floresce e frutifica o ano inteiro.

Passiflora foetida é única, entre as espécies estudadas, que possui estípulas e brácteas pinatissectas e tricomas glandulares.

7. Passiflora misera Kunth, Nov. Gen. Sp. 2: 136. 1817.

Figs. 1e, 2h-i

Caule achatado, glabro a pubescente. Estípulas linear-subuladas, caducas. Pecíolo eglanduloso. Folhas membranáceas, 2-3-lobadas, glabrescentes, lobo central reduzido, ápice retuso a levemente acuminado, lobos laterais de ápices agudos, base truncada a aguda, subpeltada, margem inteira, manchas ocelares-10, 2 basais, 8 ao longo das nervuras secundárias. Flores eretas, solitárias; brácteas alternas, verdes, lineares a setáceas, eglandulosas, caducas; hipanto curto-campanulado; sépalas, corno ausente; pétalas brancas a verde-claras; corona 2-seriada, filamentosa, série externa filiforme, violácea, série interna linear, ápice atenuado, brancoesverdeados; opérculo membranoso, plicado, margem filamentosa; límen ausente; androginóforo reto; ovário oblongoide a elipsoide, glabro; estiletes 3. Fruto ovoide a elipsoide, glabro; sementes ovaladas, transversalmente sulcadas.

Material examinado: Mata da Zambana, 17.VII.2007, fl., D. Araújo et al. 348 (UFP, IPA). 
Material adicional: BRASIL. PERNAMBUCO: Recife, Jardim Botânico do Recife, 2.IV.1996, fl. e fr., I.C.S. Machado (UFP 48029).

Amplamente distribuída no Neotrópico e no Brasil ocorre em todas as regiões, em baixas altitudes (Nunes \& Queiroz 2006). Na USJ é comumente encontrada nas bordas florestais parcialmente expostas ao sol. Floresce e frutifica de outubro a junho.

É confundida com $P$. rubra L., No entanto, esta espécie pode ser diferenciada pelo caule cilíndrico e frutos avermelhados.

8. Passiflora silvestris Vell., Fl. Flumin. Ícones 9 , Tab. 74. 1827. Figs. 1f, 2j

Caules cilíndrico, entrenós curtos no ápice, glabro. Estípulas foliáceas, oval-lanceoladas, persistentes. Pecíolo biglanduloso, glândulas estipitadas, orbiculares, verde-escuras, centroapicais. Folhas membranáceas a subcoriáceas, inteiras, glabras, oblongo-lanceoladas, ápice obtusomucronado, base arredondada a cordada, margem inteira. Flores eretas, solitárias; brácteas verticiladas, verdes, oblongo-lanceoladas a oval-lanceoladas, eglandulosas, persistentes; hipanto cilíndricocampanulado; sépalas corniculadas; pétalas brancas; corona 2-seriada, filamentosa, branca, série externa filiforme, série interna claviforme; opérculo liso, margem filamentosa; límen cupuliforme, crasso; androginóforo reto; ovário elipsoide, glabro; estiletes 3. Fruto obovoide-elipsoide, glabro; sementes obovadas, alveoladas ou reticuladas.

Material examinado: Mata da Piedade, 05.IX.2007, fl. e fr., D. Araújo et al. 478 (UFP, IPA).

Endêmica do Brasil, ocorrendo desde a Paraíba até o Rio de Janeiro, em áreas de Caatinga, Floresta Atlântica e Cerrado (Nunes \& Queiroz 2006). Na USJ, foi encontrada em bordas de mata ou clareiras sempre associadas a corpos d'água. Floresce e frutifica o ano inteiro.

Passiflora silvestris em estado vegetativo pode ser confundida com $P$. contracta, que também possui folhas inteiras, mas diferenciam-se pelos ramos congestos no ápice, flores solitárias e 3 estiletes.

\section{Passiflora suberosa L., Sp. pl. 2: 958. 1753.}

Figs. 1h, 2k

Caule cilíndrico a achatado, suberoso, pubescente. Estípulas linear-subuladas, persistentes. Pecíolo biglanduloso, glândulas estipitadas, côncavas, verdes, apicais. Folhas membranáceas, inteiras a 3-lobadas, pubescentes, linear-lanceoladas a oval-lanceoladas, ápices agudos, base cuneada a cordada, margem inteira. Flores eretas, pareadas; brácteas alternas, verdes, linear-setáceas, eglandulosas, caducas; hipanto curto-campanulado; sépalas não corniculadas; apétalas; corona 2-seriada, filamentosa; série externa filiforme, verde-amarelada; série interna claviforme, verde-vinácea; opérculo membranáceo, plicado, margem denticulada; límen anelar, livre; androginóforo reto; ovário globoide ou ovoide, glabro; estiletes 3. Fruto globoide ou ovoide, glabros; sementes reticuladas.

Material examinado: Mata dos Macacos, 18.IV.2008, fl., J. Irapuan 21 (IPA).

Amplamente distribuída nos Neotrópicos (Nunes \& Queiroz 2006), inclusive no Brasil. Na USJ, foi coletada em áreas de vegetação secundária e solo pedregoso. Floresce e frutifica o ano inteiro.

Facilmente reconhecida pelo caule suberoso e flores apétalas.

10. Passiflora watsoniana Mast., Gard. Chron. 26: 648. 1886. Figs. 1g, 21-m

Caule cilíndrico, glabro. Estípulas foliáceas, reniformes, margem serreada, persistentes. Pecíolo 2-4 glanduloso, glândulas estipitadas, orbiculares, verdes, apicais. Folhas membranáceas, 3-lobadas, glabras, ápices obtusos, base subpeltada, margem inteira, glândulas-4 nos sinus. Flores eretas, solitárias; brácteas alternas, verdes, lineares, eglandulosas, caducas; hipanto campanulado; sépalas corniculadas; pétalas lilás; corona multisseriada, filamentosa, séries externas 2, filiformes, lilás, séries internas claviformes, vináceas, filiformes; opérculo liso, margem filamentosa; límen cupuliforme, membranáceo; androginóforo reto; ovário ovoide, glabro; estiletes 3. Frutos globoide, glabros; sementes ovaladas, alveolado-foveadas.

Material examinado: Mata do Pezinho, 11.I.2008, fl., D. Araújo 591 (UFP, IPA). Mata de Piedade, 01.II.2007, fr., D. Araújo 150 (UFP, IPA); 22.III.2007, fr., D. Araújo 197 (UFP, IPA); Mata de Zambana, 21.III.2007, fr., $D$. Araújo 187 (UFP, IPA).

Endêmica da Floresta Atlântica e segundo Cervi et al. (2011) com ocorrência da Paraíba até Minas Gerais. Na USJ é a espécie mais abundante, com ocorrência na borda dos fragmentos florestais estudados. Floresce de novembro a abril e frutifica de dezembro a maio.

Pode ser confundida com $P$. amethystina J.C. Mikan., mas diferencia-se pela margem foliar serreada. 


\section{Agradecimentos}

Agradecemos ao Bundesministerium für Bildung um Forshcung (BMBF), National Science Foundation (NSF) e CNPq, o financiamento dos estudos na Usina São José; aos proprietários, o apoio logístico e Regina Oliveira, as ilustrações.

\section{Referências}

Amorim, B.S. \& Alves, M. 2011. Flora da Usina São José, Igarassu, Pernambuco: Myrtaceae. Rodriguésia 62: 499-514.

Angiosperm Phylogeny Group - APG. 2009. An update of the Angiosperm Phylogeny Group classification for the orders and families of flowering plants: APG III. Botanical Journal of the Linnean Society 161: 105-121.

Araújo, D.A. \& Alves, M. 2007. Passiflora foetida L.: Quantas variedades existem no estado de Pernambuco? Revista Brasileira de Biociências 5: 852-854.

Araújo, D.A. \& Alves, M. 2010. Climbing plants of a fragmented area of lowland Atlantic Forest, Igarassu, Pernambuco (northeastern Brazil). Phytotaxa 8: 1-24.

Buril, M.T. \& Alves, M. 2011. Flora da Usina São José, Igarassu, Pernambuco: Convolvulaceae. Rodriguésia 62: 93-105.

Cervi, A.C. 1997. Passifloraceae do Brasil. Estudo do gênero Passiflora L., subg. Passiflora. Fontqueria 45: 1-91.

Cervi, A.C.; Milward-de-Azevedo, M.A.; Bernacci, L.C. \& Nunes, T.S. 2012. Passifloraceae. In: Forzza, R.C. et al. (eds.). Lista de espécies da flora do Brasil. Jardim Botânico do Rio de Janeiro. Disponível em $<$ http://floradobrasil.jbrj.gov.br.2012.fb012506>. Acesso em 2 Ago 2012.
Deginani, N.B. 2001. Las espécies argentinas del género Passiflora (Passifloraceae). Darwiniana 39: 43-129.

Gonçalves, E.G. \& Lorenzi, H. 2007. Morfologia vegetal. Instituto Plantarum,. Nova Odessa. 431p.Killip, L. P. 1938. The American species of Passifloraceae. Field Museum of Natural History, Botanical Series 49: 1-613.

Melo, A.; Alves-Araújo, A. \& Alves, M. 2010. Burmanniaceae e Gentianaceae da Usina São José, Igarassu, Pernambuco. Rodriguésia 61: 431-440.

Mori, S.A.; Mattos-Silva, L.A.; Lisboa, G. \& Coradin, L. 1985. Manual de manejo do herbário fanerogâmico. Centro de Pesquisas do Cacau, Ilhéus. 97p.

Nunes, T.S. \& Queiroz, L.P. 2006. Flora da Bahia: Passifloraceae. Sientitibus Série Ciências Biológicas 6: 194-226.

Pessoa, E. \& Alves, M. 2011. Flora da Usina São José, Igarassu, Pernambuco: Orchidaceae. Rodriguésia 62: 341-346.

Pontes, T.A.; Andrade, I.M. \& Alves, M. 2010. Flora da Usina São José, Igarassu, Pernambuco: Araceae. Rodriguésia 61: 680-704.

Souza, V.C. \& Lorenzi, H. 2008. Botânica sistemática. Instituto Plantarum, Nova Odessa. 704p.

Ulmer, T. \& MacDougal, J.M. 2004. Passiflora: Passionflowers of the world. Timber Press, Cambridge. 430p.

Vitta, F.A. \& Bernacci, L.C. 2004. A new species of Passiflora in section Tetrastylis (Passifloraceae) and two overlooked species of Passiflora from Brazil. Brittonia 56: 89-95.

Yoshikawa, K.; Katsuta, S.; Mizumori, J. \& Arihara, S. 2000. Four cicloartane triterpenoids and six related saponins from Passiflora edulis. Journal Natural Products 63: 1229-1234. 